\title{
Resonances detected on a historical tower under bells' forced vibrations
}

\author{
Salvador Ivorra \\ University of Alicante, Spain \\ sivorra@ua.es, bttp://orcid.org/0000-0002-8647-8173 \\ Dora Foti, Mariella Diafero, Vitantonio Vacca \\ Politecnico di Bari, Italy \\ dora.foti@poliba.it, http:// orcid.org/0000-0002-9731-3497 \\ mariella.diaferi@@poliba.it, https://orcid.org/0000-0003-2780-1142 \\ vitantonio.vacca@poliba.it \\ David Bru \\ University of Alicante, Spain \\ david.bru@ua.es, https:/ / orcid.org/0000-0001-7567-1560
}

\begin{abstract}
The aim of the paper is to perform a preliminary assessment of the dynamic behavior of the bell tower of Basilica Church "S.S. Medici", one of the most important church in the town of Bitonto, Bari, Italy. The tower is $55 \mathrm{~m}$ tall and it is made in reinforced concrete. It is totally disconnected from the main structure of the Church. The structural behavior of the tower has been investigated by performing dynamic experimental tests, which have been executed in two different forcing conditions: recording the vibrations induced only by ambient loads, and, then the ones due to ambient loads and to the excitation produced by the bells. Four bells are housed in the lower bell chamber on a concrete bell frame, four more bells are housed at a higher level bell frame. All the bells are directly connected to the tower and swing in the same direction, so that their movement introduces a dynamic excitation on the tower. The experimental records have detected excessive movements on the tower when the bells swing.
\end{abstract}

KeYwORDS. Dynamic test; Concrete; OMA; Bell tower; Bell swinging.

\section{OPEN ACCESS}

Citation: Ivorra, S., Foti, D., Diafero, M., Vacca, V., Bru, D., Resonances detected on a historical tower under bells' forced vibrations, Frattura ed Integrità Strutturale, 46 (2018) 203-215.

Received: 28.06 .2018

Accepted: 04.09.2018

Published: 01.10.2018

Copyright: (C) 2018 This is an open access article under the terms of the CC-BY 4.0, which permits unrestricted use, distribution, and reproduction in any medium, provided the original author and source are credited. 


\section{INTRODUCTION}

7 he preservation of the cultural heritage is a topic of great importance for our societies. Thus, several researchers have focused their attention on the techniques, which allow the definition of a refined description of the behavior of such structures with the aim of evaluating their vulnerability and/or designing retrofitting interventions [1-5].

Among the typologies which are wide spread in the Italian building patrimony, the towers are the ones characterized by a high slenderness and, consequently, may be more vulnerable to horizontal forces like the ones induced by wind, earthquake or bells' swinging. Due to this characteristic, these structures may be investigated by means of in-situ dynamic tests, which have the advantage of allowing a description of the global behavior. In situ tests are compatible with almost all geometrical characteristics of the examined tower, and also with almost all the service conditions [6-8]. Indeed, the use of "classic" testing techniques cannot be adopted because they provide only "local" information, which cannot be sufficient for the definition of a reliable numerical model, the crucial goal for the evaluation of the seismic vulnerability and safe level of the examined structure.

As historical material, reinforced concrete (RC) has more than one century of life and many singular structures have been designated with this structural material. Many studies have been carried out adopting the aforementioned dynamic experimental techniques but almost all the examined cases deal with the evaluation of the modal parameters of masonry towers [9-11].

Many of these researches use the results of the modal parameters' identification to evaluate the unknown mechanical characteristics. This aim is obtained by updating a numerical model of the examined tower in order to match the experimental results. Almost all the cases described in the technical literature regard masonry structures, while few studies refer to structures realized with different structural materials. In [9] a tower realized in cyclopic concrete is examined, moreover [8] deals with the dynamic identification of a tower whose walls are made of a concrete core covered with stone blocks. However, by the Authors' knowledge, in the literature no studies regard towers with concrete moment resisting frames under dynamic loads generated by bells with a high level of accelerations.

On such basis the here examined bell tower has been chosen because it is characterized by a concrete frame. Moreover, during the bells' swinging the bell tower shows high amplitude vibrations. Some authors studied the effect of these vibrations on the interaction with the bell tower such as in [12-14].

\section{THE SS. MEDICI BELL TOWER}

he bell tower was realized later with respect to the construction of the Pontifical Basilica of the SS. Medici, the latter started in 1960. Bishop Marena entrusted the task of designing the great panoramic bell tower to the bitontine architect Prof. Antonio Scivittaro.

On 23 February 1974, Msgr. Aurelio Marena blessed the first stone of the panoramic bell tower in the presence of civilian and military authorities, and a multitude of devotees [15].

The bell tower is a framed reinforced concrete structure, with masonry walls made with gasbeton blocks and covered with rectangular bricks $(23 \times 12 \times 5 \mathrm{~cm})$ of red color. It is about 60 meters tall and consists of eight floors with a quadrangular base, morphologically it is a pyramidal trunk. Inside, a large staircase of 250 stone steps, which leads to the bell tower, is situated in the East side and an elevator shaft is located in the West side.

The tower has a quadrangular cross section oriented to the N-S direction. In each side, near to the corner, two variable section columns support the tower. These RC elements have a cross section of $0.6 \mathrm{~m} \times 1.7 \mathrm{~m}$ at the base, while at the seventh floor the cross section reduces to $0.3 \mathrm{~m} \times 0.5 \mathrm{~m}$ (Fig. 1). The main access is situated in the North side.

In 1990, the top of the tower was refined by a clock tower from Trebino Company in Treviso, placed here by gift from the town of Bitonto.

There is a Belvedere floor at $36.5 \mathrm{~m}$, realized by a reinforced concrete terrace, from which it is possible to enjoy an unlimited panorama, including the Adriatic Sea.

Eight bells are situated in two different floors, the four bigger bells are at $44 \mathrm{~m}$ (Fig. 1 - right). They were cast by the Fondelli Marinelli of Agnone in Molise Region. These bells are enriched with original and magnificent bas-reliefs that decorate their surfaces. Tab. 1 shows the main characteristics of these four bigger bells, and Fig. 2 shows in detail the position and direction of swinging of each bell, all in the N-S direction.

From November 1974 the bells started to swing, spreading their song along all the town. 

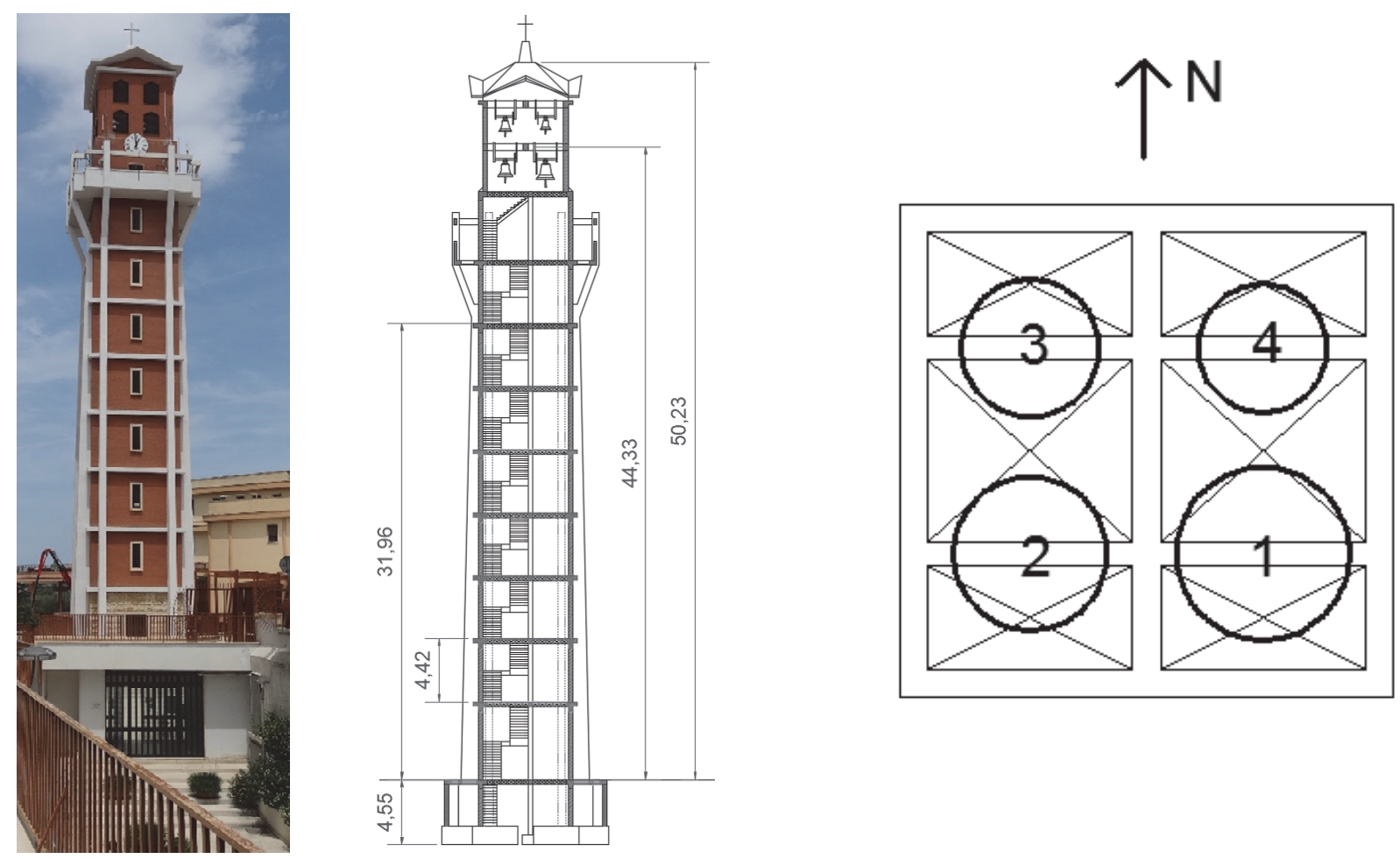

Figure 1: The SS. Medici bell tower: Left: General view of the Bell tower. Center: view of the vertical section (dimensions in m). Right: Disposition of the main bells located at $44.33 \mathrm{~m}$ from the ground level.

All these bells swing according the Central European system [16] in the N-S direction. This system is well described in the German Standard DIN4178 [17] where the vertical and horizontal forces generated by the bells and the possible interaction between the main frequencies of the bell tower and bells is presented.

\begin{tabular}{ccccc}
\hline Number of bell & Name of bell & Diameter $(\mathbf{m})$ & Weight $(\mathbf{k N})$ & Swing $(\mathbf{r a d} / \mathbf{s})$ \\
1 & Santi Medici & 1.05 & 7.5 & 2.83 \\
2 & Aurelio Marena & 0.93 & 5.5 & 3.04 \\
3 & Il signore è presente e ti chiama & 0.835 & 4.0 & 3.25 \\
4 & Isabella Ciccolella & 0.78 & 3.5 & 3.46 \\
\hline
\end{tabular}

Table 1: Bigger bells on the tower situated at $44.3 \mathrm{~m}$ from the ground level.

It is important to remark that on this bell tower it is possible to have a sensation of movement when the bells are swinging and that the people in the bell chamber feel this sensation without the use of any instrumentation. Some antennas are situated on the belvedere terrace at $40 \mathrm{~m}$ height, these slender cantilever beams start to move some seconds after the swing of the bells, this resonance effect is observed without any instrumentation.

\section{PREliminaRy MODEL - MODAl ANALYSiS}

$\mathrm{I}$ $\mathrm{n}$ order to have an initial reference of the main frequencies of the tower and its modal response, a numerical model was developed using SAP2000 code [18]. The original structural drawings of the tower have been used to build the geometry of the model. The framed structure was simulated by modelling the vertical elements situated at each side of the structure by beam elements with a variable section from the foundation to the top of the tower. The structure was considered completely restrained at the base, moreover, its horizontal displacements have been restrained at the first level due to its real disposition (see Fig. 1). The external masonry wall is modelled as a distributed load on the frames; these loads, 
the self-weight of the structural elements and other distributed loads, which simulate the floor weight at each level were considered not only as loads but also as the masses of the tower, necessary to evaluate its dynamic behavior.
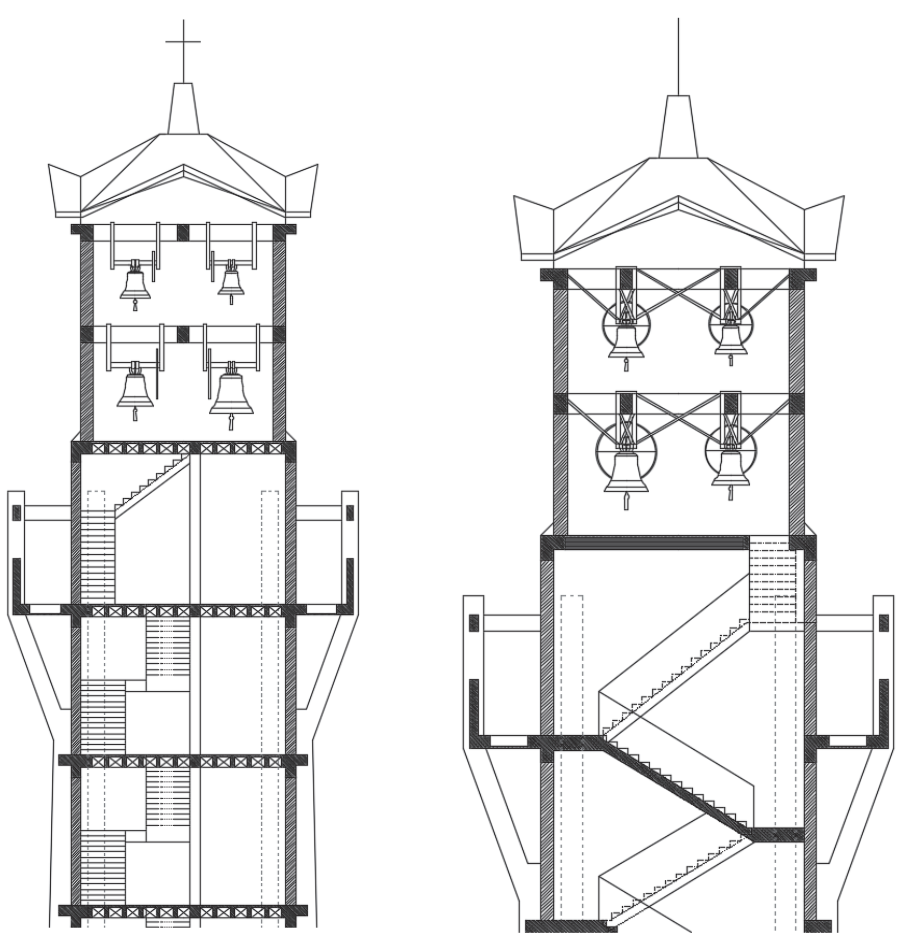

Figure 2: Belfry. Left: South View. Right: East view.

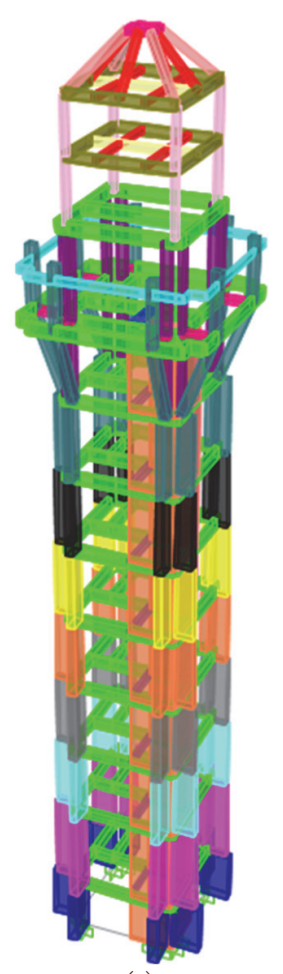

(a)

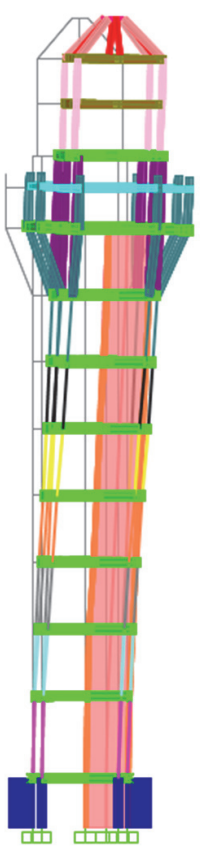

(b)

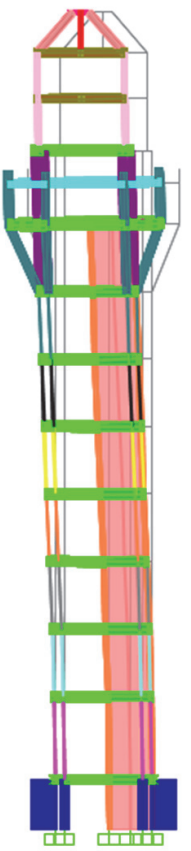

(c)

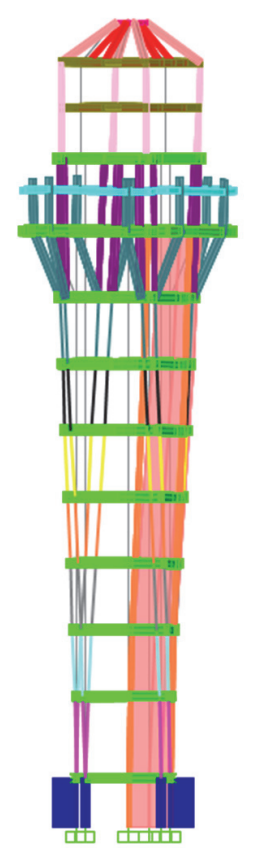

(d)

Figure 3: Numerical model of the tower. (a) General view of the model (the colors are associated to different transversal sections). (b) Bending mode in E-W direction. (c) Bending mode in N-S direction. (d) Torsional mode. 
Fig. 3 shows the preliminary results of the simulation of the tower: in the 3D view of the tower, each color represents the different sections considered to simulate the different cross sections of the vertical elements. Moreover, the results of the modal analysis are shown: Mode 1 is associated to a frequency of $0.92 \mathrm{~Hz}$ corresponding to E-W bending. The second mode is associated to a frequency of $0.95 \mathrm{~Hz}$ corresponding to N-S bending and the third numerical mode is associated to a frequency of $1.35 \mathrm{~Hz}$ corresponding to a torsional mode.

These results agree with the stiffness of the tower. In the N-S direction the tower has three vertical walls along the tower, two infilled walls on the East and West sides and the third one situated in the middle to separate the access stairs from the elevator shaft.

These preliminary results allow to get the possible response of the structure.

\section{SETUP AND EXPERIMENTAL CAMPAIGN}

$\mathrm{I}$ $\mathrm{n}$ order to develop a full-scale test on the tower under ambient vibrations and forced bells vibrations, twelve accelerometers were strategically installed on the tower to detect the main frequencies due to N-S and E-W bending modes and torsional modes. The test setup was designed to detect a possible dynamic amplification factor associated to the interaction between the main frequencies of the tower and some frequencies of the bells' swinging. For this reason, the accelerometers on the top of the tower and the accelerometers on the belfry at $44.3 \mathrm{~m}$ were specially disposed at these positions to know these possible resonances.

Fig. 4 shows a schematic view of the bell tower of SS. Medici Basilica and the position of each accelerometer indicating its direction according to the N-S view, the swing direction of all the eight bells situated on this tower.

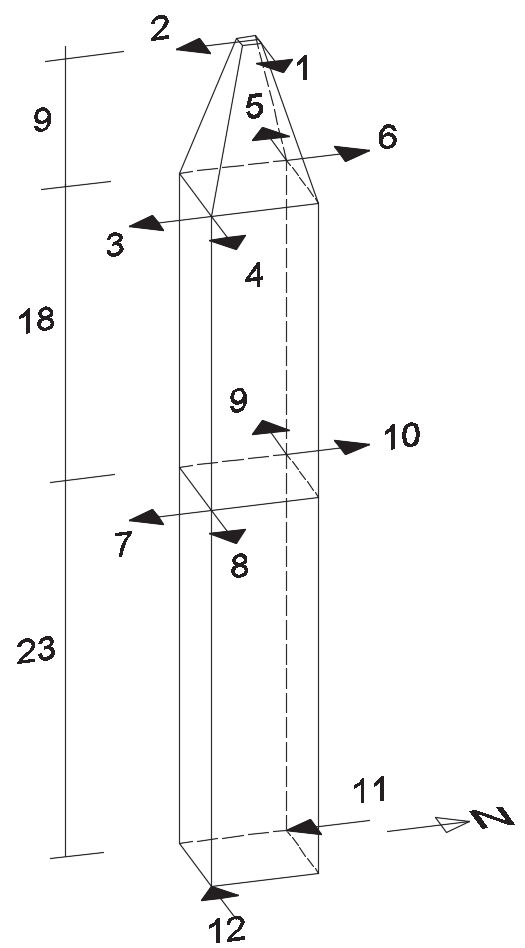

Figure 4: Simplified model of the tower. Disposition of accelerometers. The arrows indicate the acquisition direction.

The tower was instrumented with twelve seismic PCB Piezotronics (Model: 393B31 uniaxial piezo-accelerometers) placed in the N-S and E-W directions in horizontal bidirectional positions. In detail, except for the accelerometers located at the base of the tower, all the accelerometers have been installed in couple on ad hoc blocks, which ensure the orthogonality of their acquisition directions (Fig. 5- right). They were connected to an acquisition system (NI-9234) through coaxial cables with a control unit located at the $5^{\text {th }}$ floor to the controller Compact DAQ and a laptop. Fig. 5 shows the main devices used for the dynamic monitoring of the tower. 

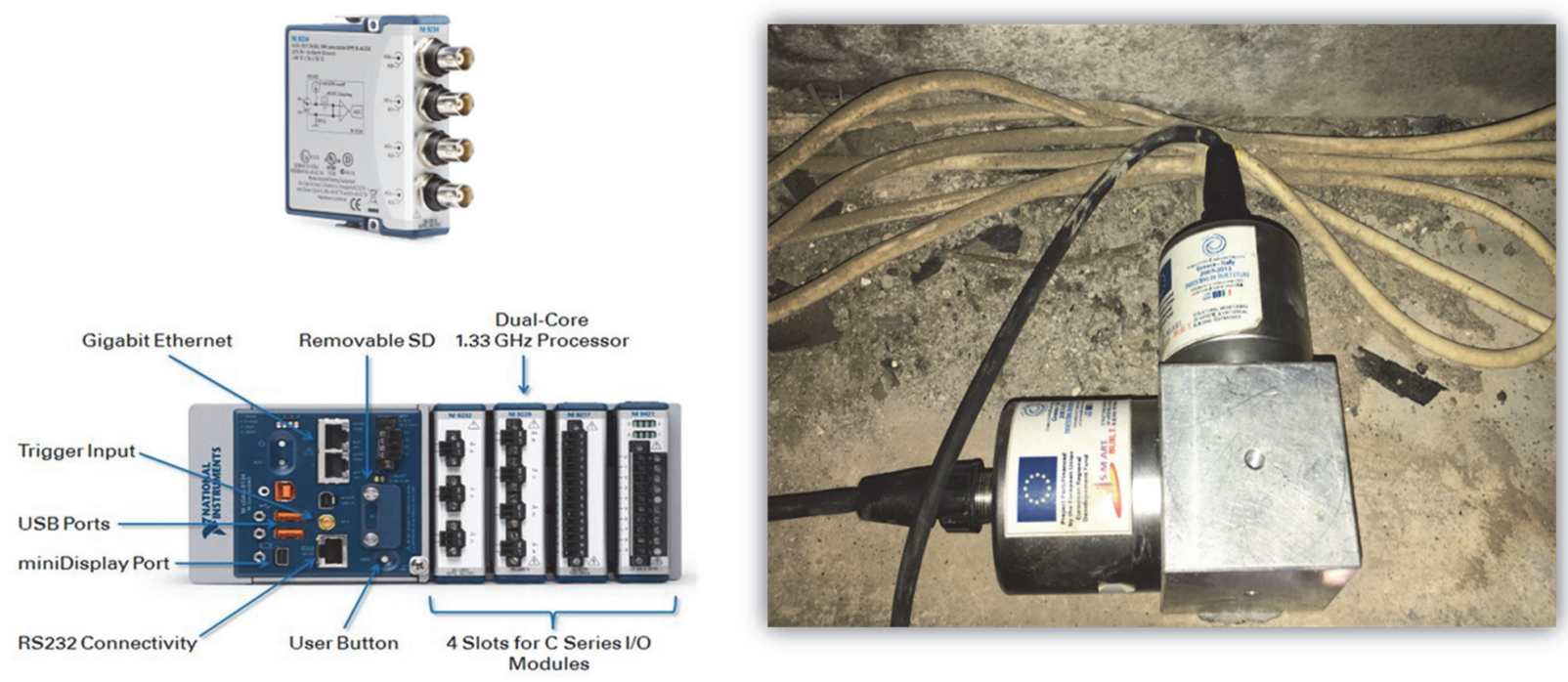

Figure 5: Devices used for the dynamic monitoring of the tower. Left: National Instruments DAQ. Right: Seismic Piezoelectric accelerometers situated on the top of the tower.

With this setup several signals have been recorded to analyze the resonance effects generated by the bell's swinging. Each recording had a duration of $720 \mathrm{~s}$ and a sampling frequency of $1024 \mathrm{~Hz}$. The recordings were acquired in five different dynamic forcing conditions:

- Ambient Noise;

- Swinging of the bigger bell (SS Medici) alone; (N-S direction)

- Swinging of the second bigger bell (Aurelio Marena) alone; (N-S direction)

- Swinging of the bell Isabella Ciccolella alone; (N-S direction)

- Swinging of all bells together. (N-S direction)

\section{PRELIMINARY RESULTS AND ANALYSIS}

o understand the response of the bell tower to the dynamic forces generated by the bells, the top N-S and E-W accelerometers were firstly considered. Fig. 6 shows the ambient response of these accelerometers.
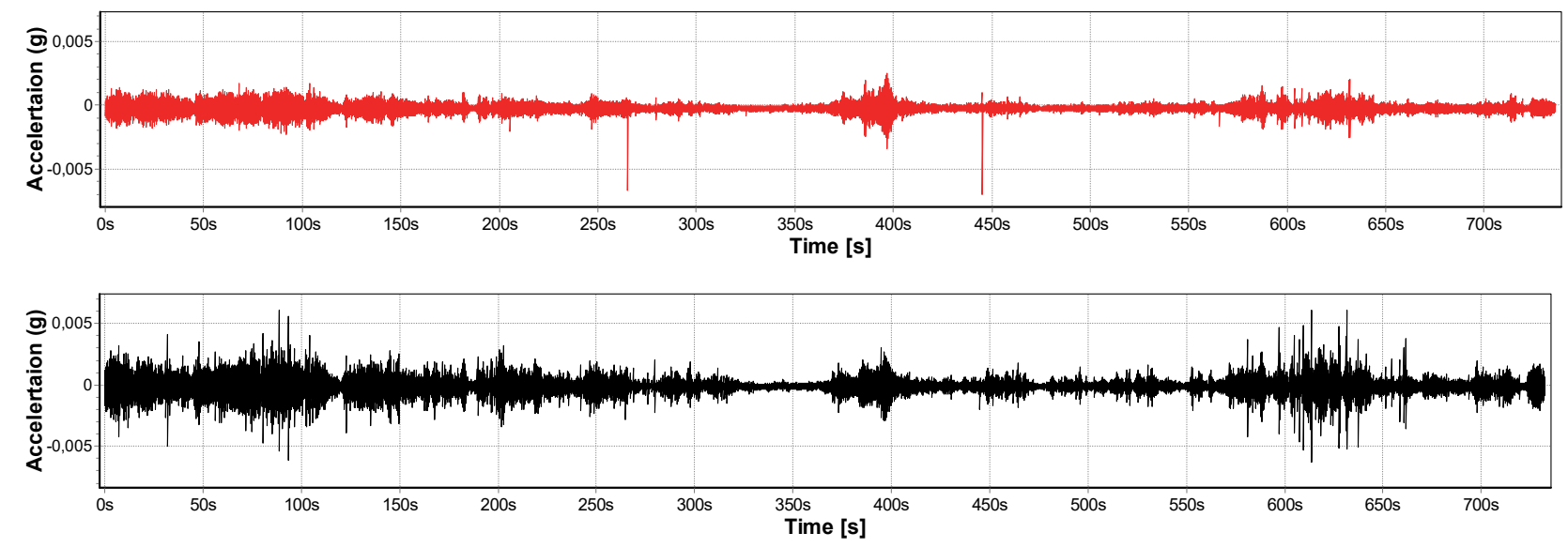

Figure 6: Acceleration recorded on the top of the tower under ambient vibrations at $1024 \mathrm{~Hz}$ sampling frequency. Up: E-W direction. Bottom: N-S direction 
When all the bells are swinging in N-S direction, a high level of acceleration has been detected, not only in N-S direction, but also in E-W direction. Fig. 7 shows that the increment of acceleration in N-S direction is immediately observed after the bells start to swing, while a similar level is achieved in the E-W direction after $35 \mathrm{~s}$ from the starting of high levels of accelerations in N-S direction. This response is generated by the torsional effects produced by the non-symmetrically excitation by the swing of bells with different weights and different swing velocities. Tab. 2 shows that the amplification generated by the swing of all the bells is higher in N-S direction than in E-W direction.

\begin{tabular}{ccccccc}
\hline & \multicolumn{2}{c}{ All bells swinging vibration } & \multicolumn{2}{c}{ Ambient vibration } & \multicolumn{2}{c}{ Amplification } \\
& $1(\mathrm{~N}-\mathrm{S})$ & $2(\mathrm{E}-\mathrm{W})$ & $1(\mathrm{~N}-\mathrm{S})$ & $2(\mathrm{E}-\mathrm{W})$ & $1(\mathrm{~N}-\mathrm{S})$ & $2(\mathrm{E}-\mathrm{W})$ \\
$\operatorname{Max}(\mathrm{g})$ & 0.0983 & 0.1251 & 0.0025 & 0.0061 & 38.66 & 20.45 \\
$\operatorname{Min}(\mathrm{g})$ & -0.0977 & -0.1126 & -0.0034 & -0.0062 & 28.35 & 18.24 \\
\hline
\end{tabular}

Table 2: Amplification generated by bells in N-S and E-W directions.
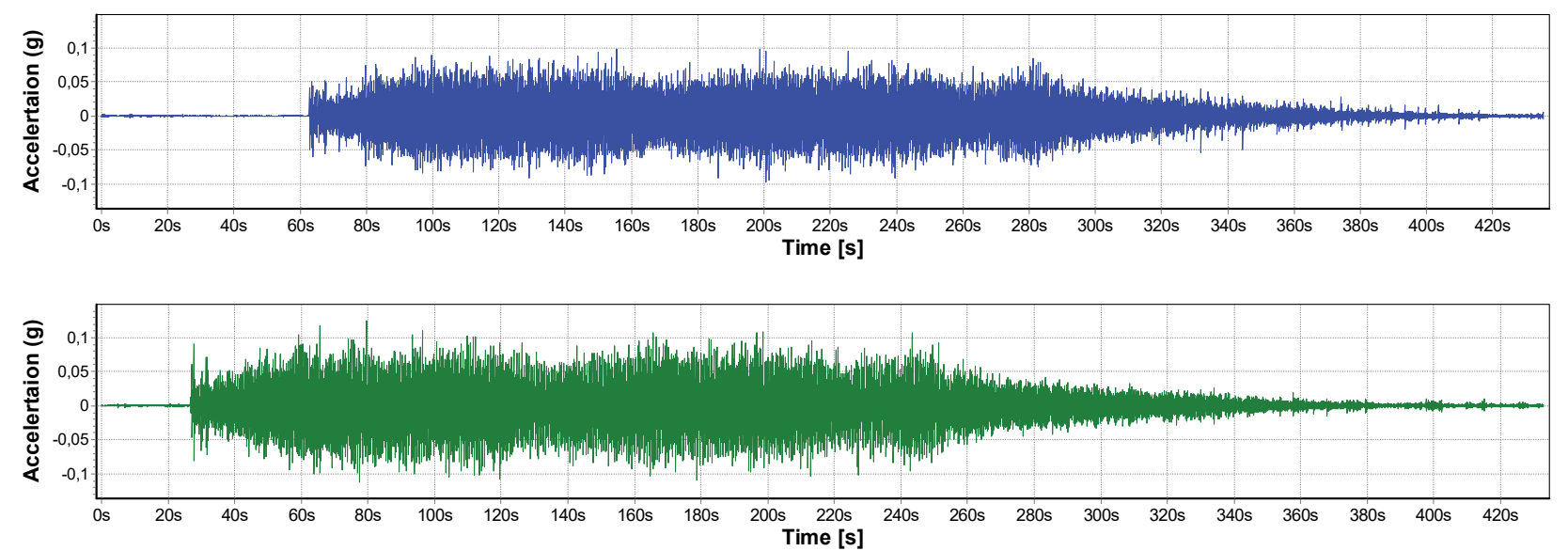

Figure 7. Acceleration registered at the top of the tower with $1024 \mathrm{~Hz}$ sampling frequency and under the swinging of all the bells at the same time. Up: E-W direction. Bottom: N-S direction

In order to delete the high frequency accelerations, which may be due to the acoustical excitations and not related to the bells swinging, a digital filter has been applied that neglets the frequencies higher than $100 \mathrm{~Hz}$. Fig. 8 represents this applied filter in which it is guaranteed that the frequencies of the structure and their interaction with the mechanical frequencies of the bells themselves are far from the filtering and therefore remain in the analyzed signals. In order to have a considerable reduction of frequencies higher than $100 \mathrm{~Hz}$ an attenuation of $80 \mathrm{~dB}$ has been applied (Fig. 8, up). In the same way, in order to achieve an adequate transition in the proximities of $100 \mathrm{~Hz}$, after testing with different configurations, a Log $200 \mathrm{has}$ been assumed to guarantee that the filtered accelerograms maintain the maximum values of the original signals in the range of $0-100 \mathrm{~Hz}$.
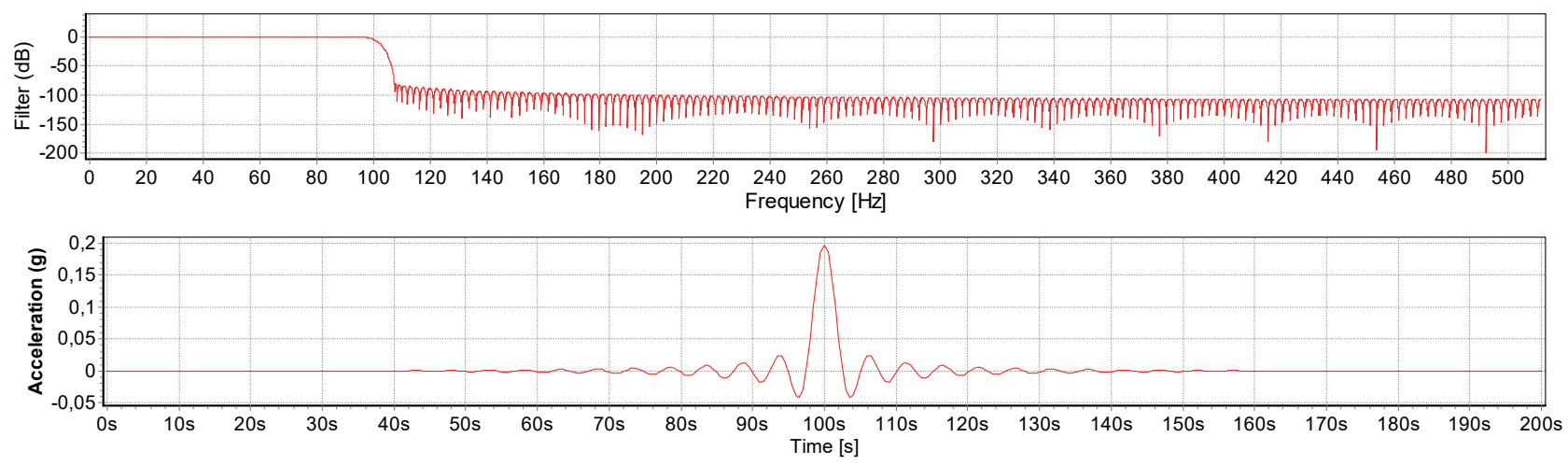

Figure 8. Digital filter applied. Up: Real filter applied. Bottom: Impulse applied. 
After the application of this filter, higher accelerations are detected in the N-S than E-W directions under ambient conditions (Fig. 9).

In the same situation under bells' forced excitation, higher accelerations have been detected in the N-S direction and lower accelerations in the E-W direction and it is clearly possible to see the effect of the sinusoidal wave generated by the swing of the bells. The N-S excitation starts when the bells start to swing, but in the E-W direction it starts $35 \mathrm{~s}$ later, the time necessary to activate the resonances of the torsional mode. When the bells stop, in the N-S direction it is observed the decay of the acceleration level but this phenomenon is practically delayed of $35 \mathrm{~s}$. The absolute maximum acceleration registered after the application of the filter is $0.0180 \mathrm{~g}$ in the N-S direction and $0.0609 \mathrm{~g}$ in the E-W direction (Fig. 10).
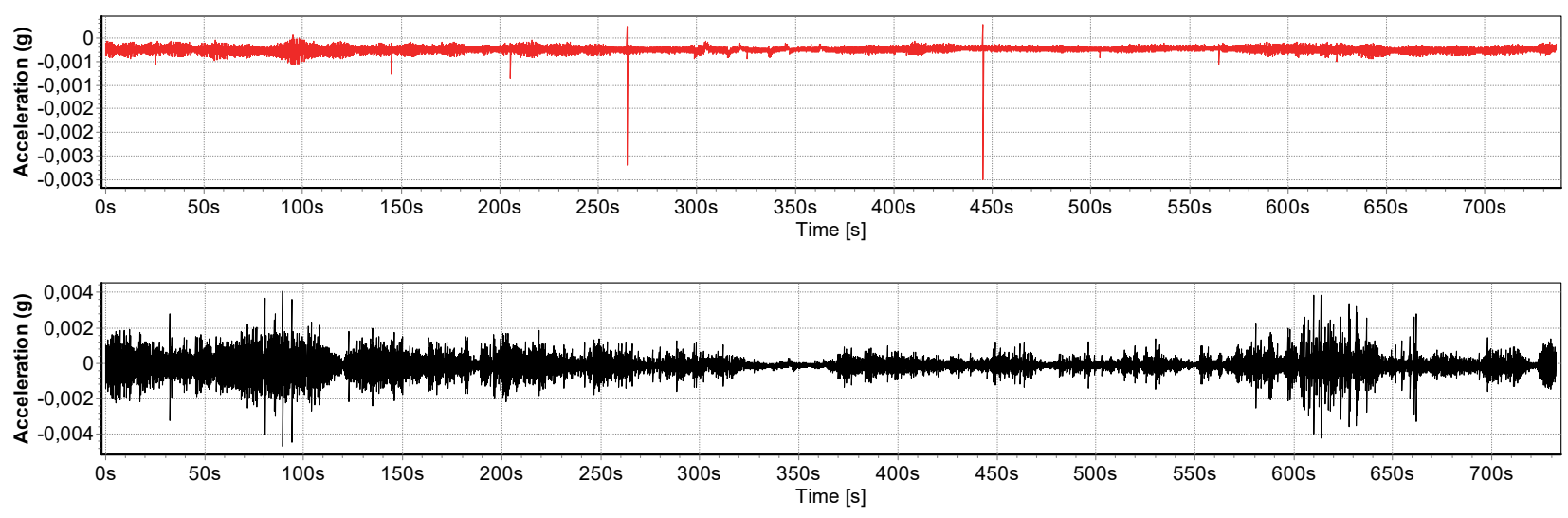

Figure 9. Acceleration recorded at the top of the tower under ambient vibrations after the application of a $0-100 \mathrm{~Hz}$ bandpass digital filter. Up: E-W direction. Bottom: N-S direction.
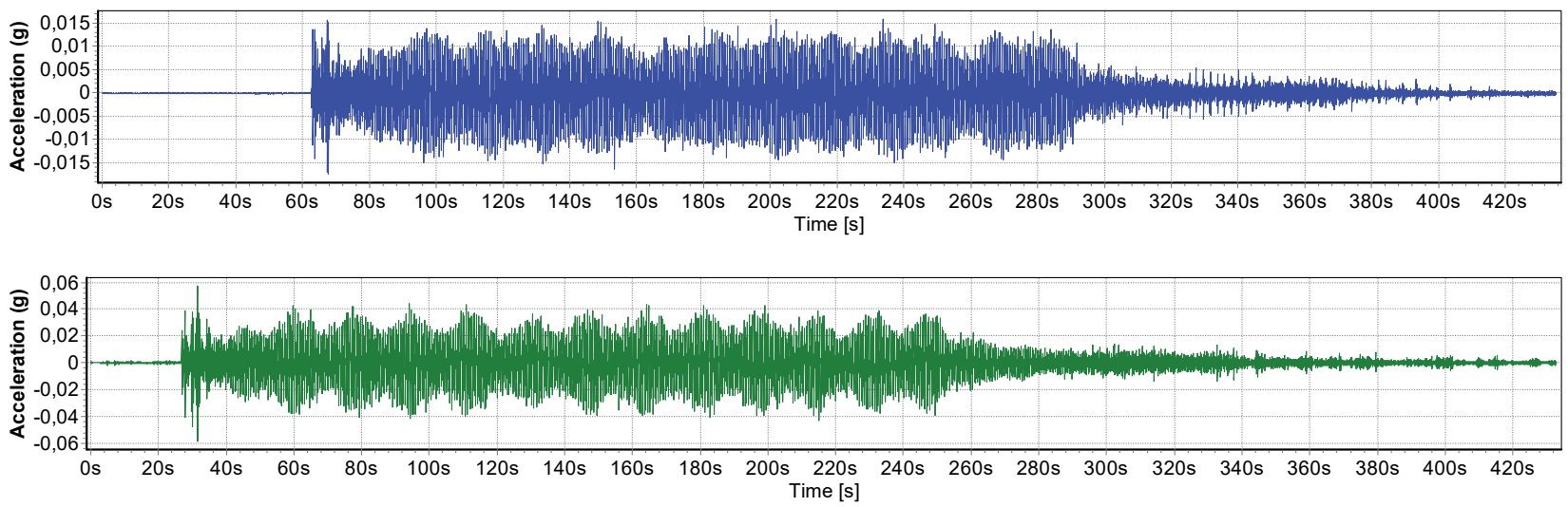

Figure 10. Accelerations recorded at the top of the tower when all the bells are swinging after the application of a 0-100 $\mathrm{Hz}$ bandpass digital filter. Up: E-W direction. Bottom: N-S direction.

\section{Operational Modal ANALysis}

I $\mathrm{n}$ order to clearly identify the main frequencies of the tower and the main modes of vibration, the Operational Modal Analysis (OMA) technique has been applied using the ARTEMIS code [19]. This experimental modal analysis (Fig. 11) allows to statistically analyse the frequencies of the tower at each time instant and in each position of the accelerometers. Fig. 11 shows the geometric distribution of sensors and their records and the slave node restrictions to assure modal displacements geometrically compatible.

Ambient recordings have been used to introduce the random excitation noise on the tower. Different statistical analyses have been applied, here the results of the stochastic subspace identification (SSI) technique are discussed, but similar results have been achieved by adopting other techniques. The SSI technique provides the following main frequencies: $1.30 \mathrm{~Hz}$, $1.35 \mathrm{~Hz}$ and $2.69 \mathrm{~Hz}$. 
Fig. 12 shows the modes associated to the main frequencies obtained by the application of OMA: the first two modes with bending-torsional components, and the third mode practically torsional.

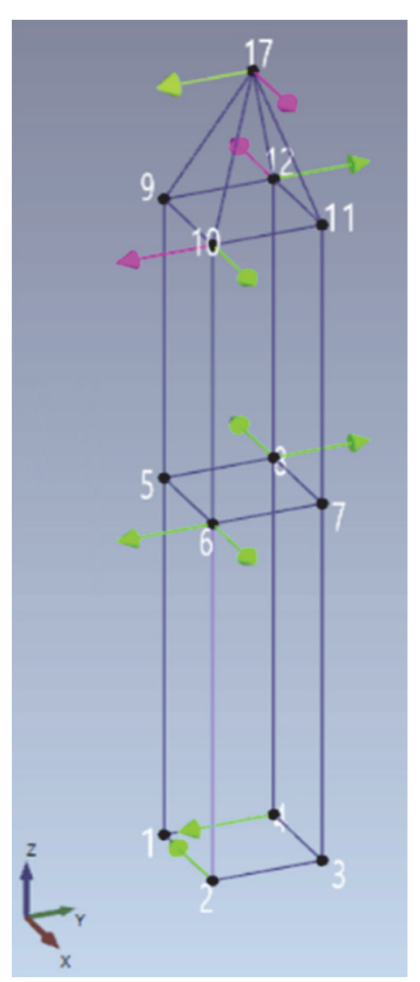

\begin{tabular}{|l|l|l|l|l|l|l|l|l|}
\hline \multicolumn{1}{|c|}{ Channels Information } & & & \\
\hline
\end{tabular}

$\operatorname{node}(\mathbf{1}, \mathbf{1})=\operatorname{node}(\mathbf{2}, \mathbf{1})$
node $(\mathbf{1}, \mathbf{2})=\operatorname{node}(\mathbf{4}, \mathbf{2})$
node $(\mathbf{3}, \mathbf{1})=\operatorname{node}(\mathbf{2}, \mathbf{1})$
node $(\mathbf{3}, \mathbf{2})=\operatorname{node}(\mathbf{4}, \mathbf{2})$
node $(\mathbf{1}, \mathbf{3})=\operatorname{node}(\mathbf{2}, \mathbf{3})=\operatorname{node}(\mathbf{3}, \mathbf{3})$
node $(\mathbf{4}, \mathbf{3})=\mathbf{0}$
node $(\mathbf{7}, \mathbf{1})=\operatorname{node}(\mathbf{8}, \mathbf{1})$
node $(\mathbf{5}, \mathbf{2})=\operatorname{node}(\mathbf{8}, \mathbf{2})$
node $(\mathbf{7}, \mathbf{2})=\operatorname{node}(\mathbf{6}, \mathbf{2})$
node $(\mathbf{5}, \mathbf{1})=\operatorname{node}(\mathbf{6}, \mathbf{1})$
node $(\mathbf{1 1}, \mathbf{1})=\operatorname{node}(\mathbf{1 2}, \mathbf{1})$
node $(\mathbf{9}, \mathbf{2})=\operatorname{node}(\mathbf{1 2}, \mathbf{2})$
node $(\mathbf{9}, \mathbf{1})=\operatorname{node}(\mathbf{1 0}, \mathbf{1})$
node $(\mathbf{1 1}, \mathbf{2})=\operatorname{node}(\mathbf{1 0}, \mathbf{2})$

Figure 11: Artemis software. Simplified tower geometry and disposition of the accelerometers. Slave nodes equations for the analysis.

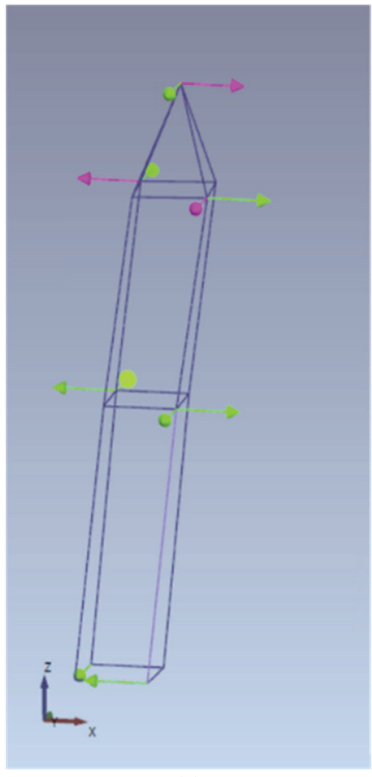

(a)

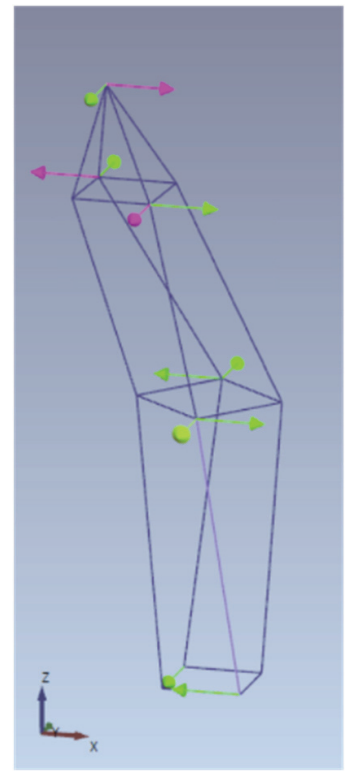

(b)

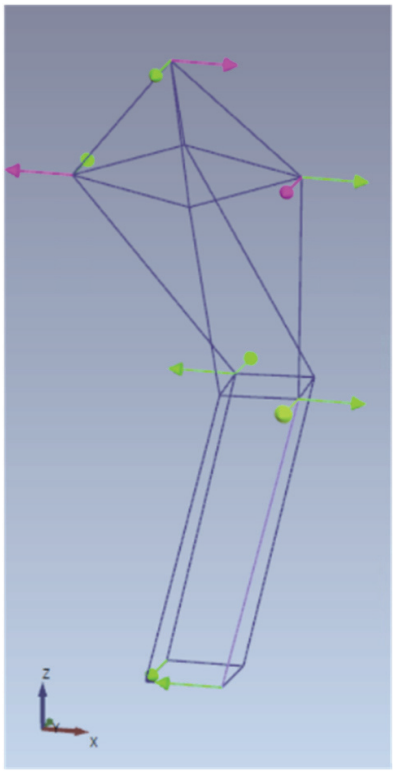

(c)

Figure 12: OMA results. (a) First bending-torsion mode. (b) Second bending-torsional mode. (c) Torsional mode. 


\section{CALIBRATION OF THE NUMERICAL MODEL}

T $\mathrm{n}$ order to identify the modal results obtained by the numerical model and by the experimental campaign, the numerical model was updated to match the experimental natural frequencies and mode shapes. The procedure is presented in Fig. 13.

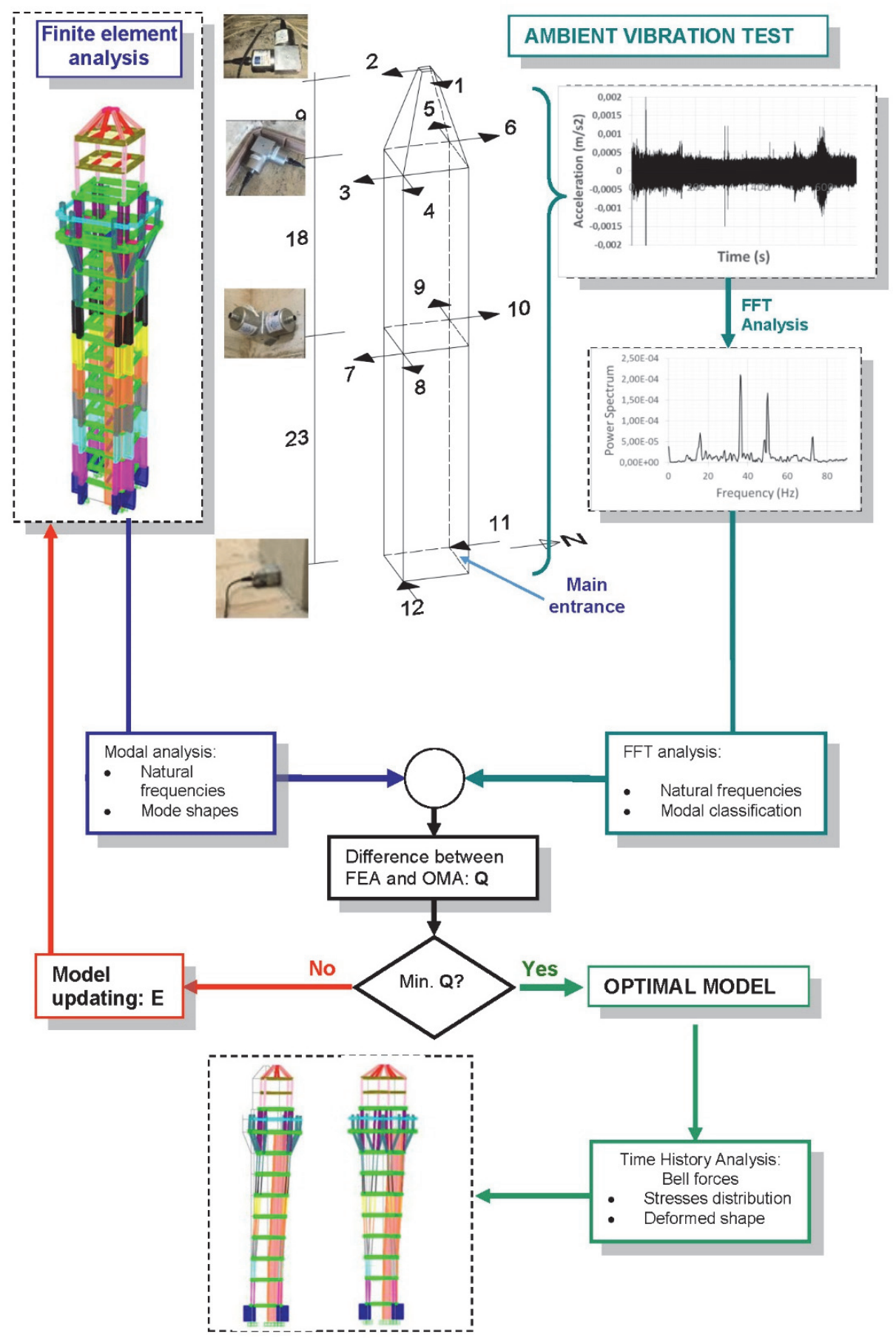

Figure 13. General setup for the dynamic identification of the tower and identification of its main dynamic characteristics. 
By an iterative process, the elastic modulus of the concrete has been modified to minimize the differences between the numerical and the experimental frequencies, assuming a fixed value for the density of the concrete of $20 \mathrm{kN} / \mathrm{m}^{3}$.

After the iterative process the Elastic Modulus of the concrete was incremented to $65000 \mathrm{~N} / \mathrm{mm}^{2}$. In this situation the new parameter includes the additional stiffness generated by the enclosure masonry walls to the overall structure. Tab. 3 shows the final results that achieve frequencies quite similar to the experimental ones.

\begin{tabular}{cccc}
\hline Frequency & Preliminary Model & Experimental & Calibrated Model \\
First $(\mathrm{Hz})$ & 0.92 & 1.30 & 1.29 \\
Second $(\mathrm{Hz})$ & 0.95 & 1.35 & 1.33 \\
Third $(\mathrm{Hz})$ & 1.35 & 2.69 & 1.85 \\
\hline
\end{tabular}

Table 3: Comparison between the main frequencies of the preliminary numerical model, the experimental identification results and the updated numerical model which includes the stiffness of the masonry walls.

\section{Discussion}

$\mathrm{I}$ $\mathrm{t}$ is important to remark the high levels of acceleration detected at the top of SS Medici bell tower when the bells are swinging. This high level of accelerations is not only in N-S direction, where the bells are swinging, but a high level of accelerations has been registered also in the E-W direction but with a delay of $35 \mathrm{~s} \mathrm{respect} \mathrm{to} \mathrm{the} \mathrm{N-S} \mathrm{direction.} \mathrm{After}$ the Finite Element Analysis and the Operational Modal Analysis, it is possible to conclude that the mode shapes associated to the main frequencies are no pure bending modes in the N-S or E-W directions, the two main modes having a diagonal component associated to a deviated bending due to the internal stiffness of the tower. The shape of these modes is associated to the geometry of the tower and the distribution of mass and stiffness along the tower, that is the effect of lateral stair in the East side and the vertical wall for the elevator shaft.

Original results recorded at $1024 \mathrm{~Hz}$ present levels of acceleration higher than the ones filtered by a passband of 0-100 Hz, but the use of this filter assures that the recorded levels are generated by the low frequencies due to mechanical excitations (swing of bells) and not by acoustical excitations generated by the sound of these bells. DIN4178 [17] refers to the first, third, and fifth harmonics of the swing forces as the components of the horizontal forces generated by the bells on their supports. Tab. 4 shows these values for each of the four bigger bells. These low frequencies mechanical excitations are close to those of the tower $(1.30 \mathrm{~Hz}, 1.35 \mathrm{~Hz}$ and $2.69 \mathrm{~Hz})$ and are responsible of these resonances.

\begin{tabular}{ccccccc}
\hline \multirow{2}{*}{$\begin{array}{c}\text { Number } \\
\text { of bell }\end{array}$} & Name of bell & $\begin{array}{c}\text { Weight } \\
(\mathrm{kN})\end{array}$ & $\begin{array}{c}\text { Swing } \\
(\mathrm{rad} / \mathrm{s})\end{array}$ & $\begin{array}{c}\text { First } \\
(\mathrm{Hz})\end{array}$ & Third $(\mathrm{Hz})$ & Fifth $(\mathrm{Hz})$ \\
1 & Santi Medici & 7.5 & 2.83 & 0.45 & 1.35 & 2.25 \\
2 & $\begin{array}{c}\text { Aurelio Marena } \\
\text { Il signore è } \\
\text { presente e ti } \\
\text { chiama }\end{array}$ & 5.5 & 3.04 & 0.48 & 1.45 & 2.42 \\
4 & $\begin{array}{c}\text { Isabella Ciccolella } \\
4\end{array}$ & 3.0 & 3.25 & 0.52 & 1.55 & 2.58 \\
\hline
\end{tabular}

Table 4: Main harmonics of the horizontal forces generated by the bigger bells according to DIN4178.

A visual analysis of the structure shows that the high level of vibration associated with the swinging of the bells induces high level of stresses that -associated with the proximity to the sea- provoked cover spalling due to corrosion effects (Fig. 14). This effect over time can be very dangerous for the structure even for vertical loads [20-22]. Some cracks have been detected on the bell frame where the bells are placed, a more detailed analysis should be developed to understand the relation between these cracks and the bell forces. 


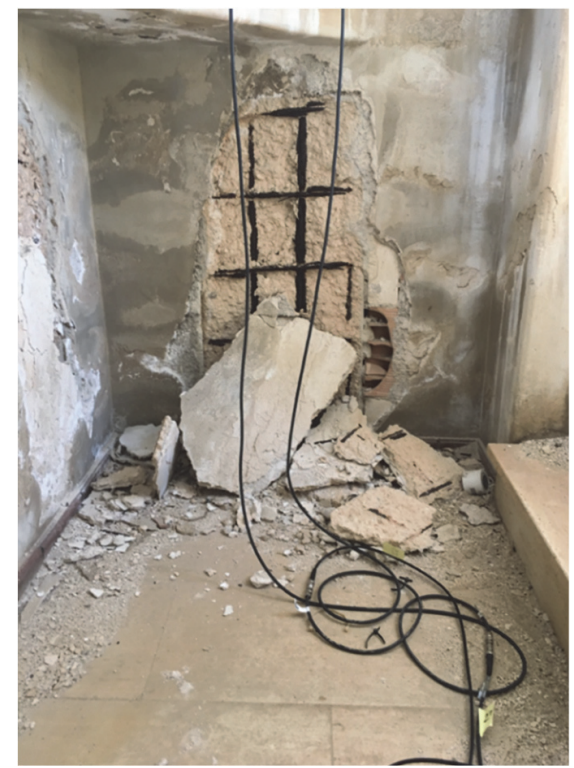

Figure 14. Corrosion effects detected on the bell chamber at a quote of $40 \mathrm{~m}$ from the ground level.

\section{CONCLUSIONS AND FUTURE DEVELOPMENTS}

A dynamic identification of a SS. Medici Bell Tower structure has been carried out. The main frequencies and mode shapes have been investigated by numerical models and by an experimental campaign applying Operational Modal Analysis. On this concrete bell tower the high levels of accelerations generated by the bells' swinging could be detected without the use of any instrumentation. By the use of accelerometers these higher values have been measured and a coupled behavior between the N-S and E-W deformations of the bell tower when the bells swing only in N-S direction has been detected. Due to this high level of accelerations and the proximity to the sea, some areas of the reinforced concrete structure present cracks and expulsion of the RC cover.

Additional studies should be developed to analyze the level of stresses of each structural member when the resonances between bells and main frequencies of the tower occur, determining the effects of the bells and searching possible solutions to reduce the high levels of accelerations in order to preserve the integrity of the tower. Unlike masonry structures, this is a slender tower with lower masses; in this case, large displacements could produce the opening of small cracks where the salted wind from the Adriatic Sea can accelerate the corrosion process of the reinforcement bars. This is a very dangerous situation for a RC structure. In future developments these studies should deal with the nonlinear analysis of this structure considering, additionally, the possible effect of seismic loads on the actual state of the RC structure. Moreover, future development should present a more accurate numerical model, including the masonry walls to have a better representation of the behavior of the tower to dynamic loads: bells and seismic loads.

\section{REFERENCES}

[1] Foti, D., Diaferio, M., Giannoccaro, N. I. and Ivorra, S. (2015). Structural identification and numerical models for slender historical structures, in Handbook of Research on Seismic Assessment and Rehabilitation of Historic Structures, P. Asteris and V. Plevris, pp. 674-703.

[2] Ubertini, F., Cavalagli, N., Kita, A. and Comanducci, G. (2018). Assessment of a monumental masonry bell-tower after 2016 central Italy seismic sequence by long-term SHM, Bull. Earthq. Eng., 16(2), pp. 775-801.

[3] Bastianini, F., Corradi, M., Borri, A. and Di Tommaso, A. (2005). Retrofit and monitoring of an historical building using 'smart' CFRP with embedded fibre optic Brillouin sensors, Constr. Build. Mater., 9(7), pp. 525-535.

[4] European Commitee for Standardization, Eurocode 8 Part 3 Eurocode 8 Part 3 Assessment and retrofitting of buildings. Brussels, (2005).

[5] Diaferio, M., Foti, D., Giannoccaro, N. I. and Ivorra, S. (2014). Optimal model through identified frequencies of a masonry building structure with wooden floors, Int. J. Mech., 8(1). 
[6] Bartoli, G., Betti, M. and Giordano, S. (2013). In situ static and dynamic investigations on the 'Torre Grossa' masonry tower, Eng. Struct., 52, pp. 718-733.

[7] Bartoli, G., Betti, M. and Monchetti, S. (2017). Seismic Risk Assessment of Historic Masonry Towers: Comparison of Four Case Studies, J. Perform. Constr. Facil., 31(5).

[8] Diaferio, M., Foti, D., Gentile, C., Giannoccaro, N. I. and Saisi, A. (2015). Dynamic testing of a historical slender building using accelerometers and radar, in 6th International Operational Modal Analysis Conference, IOMAC 2015.

[9] Diaferio, M., Foti, D. and Mongelli, M. (2011). Operational Modal Analysis of a Historic Tower in Bari, in Civil Engineering Topics, 4, pp. 335-342.

[10] Gentile, C., Saisi, A. and Cabboi, A. (2014). Structural Identification of a Masonry Tower Based on Operational Modal Analysis, Int. J. Archit. Herit., 9(2), pp. 98-110.

[11] Foti, D. (2014). Non-destructive techniques and monitoring for the evolutive damage detection of an ancient masonry structure, Key Eng. Mater., 628, pp. 168-177.

[12] Ivorra, S., Pallarés, F. J. and Adam, J. M. (2009). Dynamic behaviour of a modern bell tower - A case study, Eng. Struct., 31(5).

[13] Lepidi, M., Gattulli, V. and Foti, D. (2009). Swinging-bell resonances and their cancellation identified by dynamical testing in a modern bell tower, Eng. Struct., 31(7), pp. 1486-1500.

[14] Ivorra, S., Pallarés, F. J. and Adam, J. M. (2011). Masonry bell towers: Dynamic considerations, Proc. Inst. Civ. Eng. Struct. Build., 164(1).

[15] Cannito, G. (2017). Il Carisma del Vescovo Mons. Aurelio Marena (1950-1978) nella Basilica pontificia dei Santi Medici Cosma e Damiano"- Note storiche pastorali nella Curia Vescovile di Bitonto.

[16] Ivorra, S., Palomo, M. J., Verdú, G. and Zasso, A. (2006). Dynamic forces produced by swinging bells, Meccanica, 41(1).

[17] DIN 4178 2005-04: Glockentürme [In German]. Normenausschuss Bauwesen (NABau) im DIN, (2005), pp. 32.

[18] CSI, SAP2000. Analysis Reference Manual, CSI: Berkeley (CA, USA): Computers and Structures INC. (2014).

[19] ARTeMIS: Ambient Response Testing and Modal Identification Software. Structural Vibration Solutions A/s, Denmark, (2016).

[20] Adam, J. M., Moreno, J. D., Bonilla, M. and Pellicer, T. M. (2016). Classification of damage to the structures of buildings in towns in coastal areas, Eng. Fail. Anal., 70, pp. 212-221.

[21] Moreno, J. D., Bonilla, M., Adam, J. M., Borrachero, M. V. and Soriano, L. (2015). Determining corrosion levels in the reinforcement rebars of buildings in coastal areas. A case study in the Mediterranean coastline, Constr. Build. Mater., 100, pp. 11-21.

[22] Bru, D., González, A., Baeza, F. J. and Ivorra, S. (2018). Seismic behavior of 1960’s RC buildings exposed to marine environment, Eng. Fail. Anal., 90, pp. 324-340. 